\title{
Gynecological Surgery and the Robot
}

\author{
O. E. O’Sullivan, B. A. O’Reilly \\ Department of Urogynecology, Cork University Maternity Hospital, Cork, Ireland \\ Email: scatterjack@gmail.com
}

Received November 3, 2013; revised December 3, 2013; accepted December 10, 2013

Copyright (C 2014 O. E. O’Sullivan, B. A. O’Reilly. This is an open access article distributed under the Creative Commons Attribution License, which permits unrestricted use, distribution, and reproduction in any medium, provided the original work is properly cited. In accordance of the Creative Commons Attribution License all Copyrights (C) 2014 are reserved for SCIRP and the owner of the intellectual property O. E. O’Sullivan, B. A. O’Reilly. All Copyright (C) 2014 are guarded by law and by SCIRP as a guardian.

\begin{abstract}
As the only robotic device with FDA approval for gynecological surgery, the da Vinci ${ }^{\circledR}$ Surgical System dominates robot-assisted surgery in the field. Benefits to the Surgeon include decreased risk of neck and back injury secondary to improved ergonomics. However, patients benefit greatly due to decreased length of stay, decreased blood loss and analgesic requirements. Unfortunately the initial economic impact of purchasing and maintaining a robot is great but must be balanced with the potential savings from reduced length of stay and earlier return to normal activity. This article looks at the indications for robot-assisted surgery in gynecology. Assessing the efficacy of this modality compared to both straight stick (Laparoscopy) and open procedures. We discuss the impact and implications for surgical training imposed by robotic surgery. Furthermore, we assess the safety of robotic surgery from both the surgeons prospective and as a surgical modality.
\end{abstract}

\section{KEYWORDS}

\section{da Vinci Surgical System; Gynecology; Training; Ergonomics}

\section{Introduction}

Surgical Robots were developed to facilitate minimally invasive surgery and to assist surgeons in performing procedures that would otherwise not be possible using traditional open or laparoscopic techniques [1]. DARPA (Defense Advanced Research Projects Agency) while funding research into the possibility of a remote surgery program targeted toward battlefield triage aided the development of robotic surgery. The da Vinci ${ }^{\circledR}$ Surgical System (Intuitive Surgical, Inc., Sunnyvale, CA) was introduced to the market in 1999 and in 2000 it was cleared by the FDA (Food and Drug Authority) for minimally invasive surgery. However, it didn't gain FDA approval for gynecological surgery until 2005, while in Europe it has had full regulatory clearance and the CE (Conformité Européenne) mark since 1999 [2]. Over the past eight years, the role of the robot has expanded exponentially with many gynecological procedures now being performed with robot assistance, including prolapse surgery (sacrocolpopexy/hysteropexy), myomectomy, tubal surgery, endometriosis surgery, hysterectomy (benign and malignant), cervical surgery (benign and malignant) and adnexal surgery [3,4]. The benefits for the Surgeon include the potential for greater precision, lower error rates, shorter learning curves and superior ergonomics than conventional laparoscopy.

Robot-assisted surgery is associated with clinical benefits for the patient such as reduced estimated blood loss (EBL), decreased blood transfusion requirements, shorter length of stay (LOS), reduced peri-operative pain and analgesic requirements. The Health Technology Assessments (HTAs) conducted worldwide have agreed in principle that robotic surgery is indeed associated with benefits in terms of reduced blood loss, decreased transfusion rate, reduction in complication rates and a reduction in the length of stay [5-7]. With regard to health economics, the current robotic surgical platform has been criticized due to its cost with no regard given to the benefits to society in terms of shorter duration of stay, reduced perioperative complications and reduced transfusion requirements. Furthermore, there is the potential for earlier return to work as a consequence of reduced pain and analgesic requirements. As of December 31, 2012, there were 2585 da Vinci ${ }^{\circledR}$ Surgical Systems installed in approximately 2025 hospitals worldwide with approximately 
450,000 robot-assisted procedures across all surgical fields performed in 2012, an increase of approximately 25\% compared to 2011 [8].

\section{What Is da Vinci ${ }^{\circledR}$ Surgical System?}

The da Vinci ${ }^{\circledR}$ Surgical System, since it was first introduced has undergone modifications and upgrades to the newer models with four arms, high definition (HD) imaging with improved visual capabilities and dual console capabilities to facilitate training. In brief the System consists of three main components: the ergonomically designed console from where the Surgeon controls the operation, the patient side cart with four interactive robotic arms to which the operating instruments are attached and the high performance vision system (Figure 1). The EndoWrist $^{\circledR}$ instruments used during surgery combine 7 degrees of freedom, with 90 degrees of articulation to provide a range of motion superior to the human hand. Surgical dexterity is further improved by combining intuitive motion and fingertip control with motion scaling and tremor reduction technology. The principle of robotic surgery is that the surgeon operates unscrubbed while seated at the console, from which they are able to view the operating field in three dimensions through a stereoscopic viewer. It combines the benefits of laparoscopic surgery with ergonomic and technical advantages to the Surgeon.

\section{Robot-Assisted Gynecological Surgery}

\subsection{General Gynecology: Hysterectomy: Benign and Malignant}

One of the first publications regarding robot-assisted hysterectomy was in 2006 by Reynolds [9]. Studies have shown that robot-assisted hysterectomy is associated with a reduction in estimated blood loss [10-27], complication rates [10-14,16-30] and reduced length of stay [10-30] but is associated with longer operating times [10-22,24-30] when compared with the open approach. Compared to traditional laparoscopy the robot-assisted approach is associated with decreased operating times [12], reduced EBL, complication rates and conversion rates [10,12,14,20,23,29,31-41]. The most telling benefit to robot-assisted hysterectomy is that fewer errors are made compared with the laparoscopic approach [37]. Robot-assisted hysterectomy has been successfully used in the treatment of locally advanced cervical cancer $[42,43]$. However with regard to gynecological cancer surgery recent studies with long-term outcomes report a potential complication of port site metastasis one reported incidence is $1.9 \%$. Women with $\geq$ stage III endometrial cancer, high-grade histology and women with node positive cervical cancer had a significantly higher risk of developing a port-site metastasis. Notably, portsite metastases were four times more likely to occur in a specimen-retrieval port. The median time to occurrence

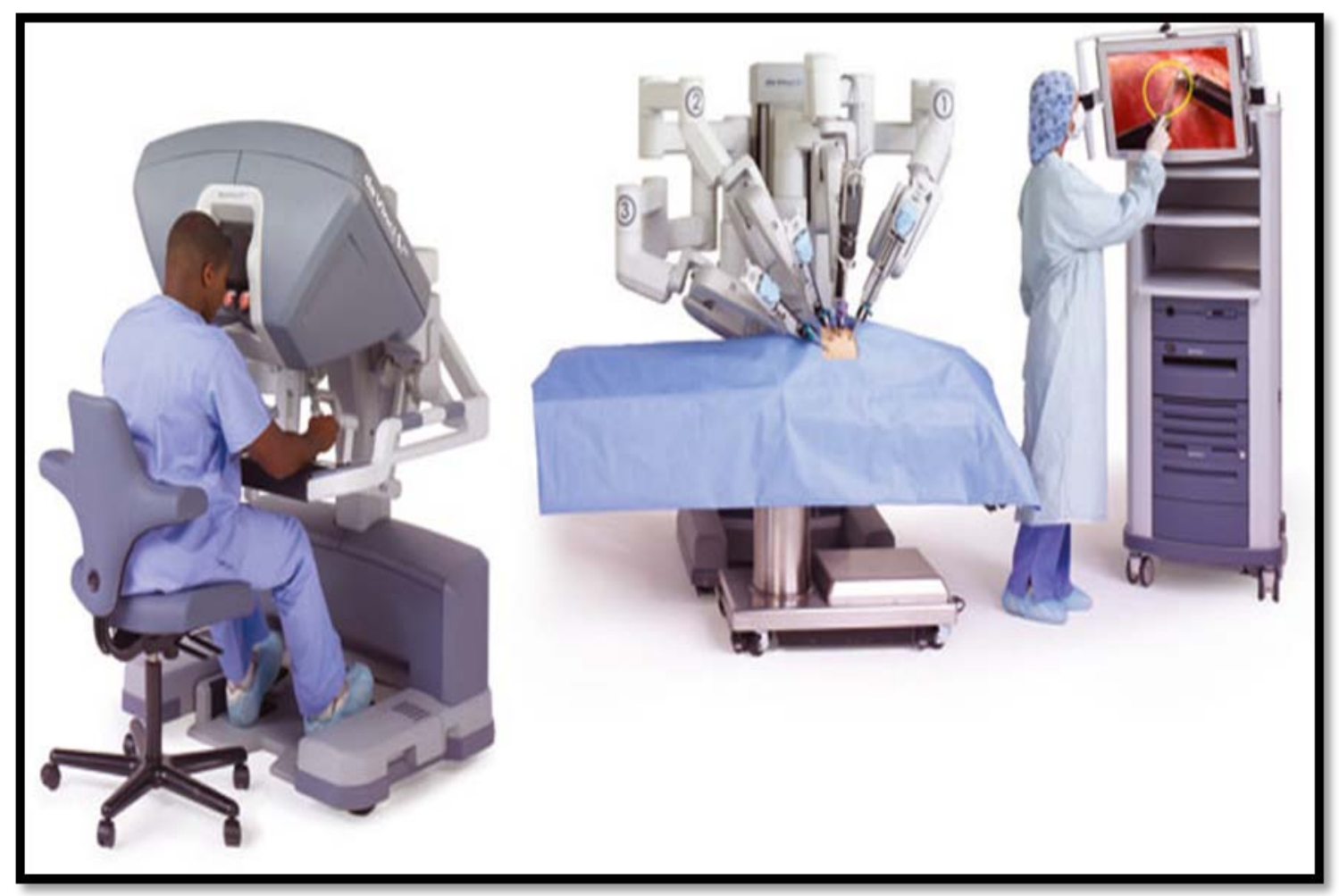

Figure 1. The main components of the da Vinci Surgical System. ${ }^{\circ} 2011$ Intuitive Surgical, Inc. 
of a port-site metastasis was 6 months [44].

\subsection{General Gynecology: Adnexal Surgery: Benign and Malignant}

With regard to the use of robotic technology in adnexal surgery Magrina analyzed the use of robotic, laparoscopy and laparotomy for secondary cytoreduction for recurrent ovarian cancer [45]. No differences were observed among the three groups for operating time, complications, complete debulking and survival. However, laparotomy seemed preferable for patients with widespread peritoneal implants, multiple sites of recurrence and/or extensive adhesions [46].

\subsection{General Gynecology: Endometriosis Surgery}

Robot-assisted approaches had reportedly been used for endometriosis surgery [47], Siesto in the largest series published regarding robot-assisted surgery for deep infiltrating endometriosis concluded robot-assisted surgery is a safe and attractive alternative to accomplish a comprehensive surgical treatment especially when bowel or bladder resections are required [48].

\subsection{Pediatric Gynecology}

Recent publications suggest a role for robot-assisted surgery for pediatric gynecology. One paper from Italy reported on six pediatric robot-assisted surgeries for adnexal pathologies. They concluded that the initial results suggest the robotic approach is safe in the pediatric population however further studies are required to assess the safety and the limits of the approach [49].

\subsection{Fertility: Myomectomy}

Gobern et al. compared myomectomy across the three surgical modalities of robot-assisted, laparoscopic and open, they concluded the robot-assisted approach was associated with longer operating times, shorter hospital stay and reduced blood loss [50]. Other studies have confirmed the longer operating time and shorter length of stay [51,52]. Of note myomectomies are notorious for blood loss especially if multiple leiomyomata require excision. The EBL was lower in the robot-assisted group compared to the open. Griffin et al. specifically assessed postoperative outcomes confirming there was a shorter length of stay and return to work associated with the robot-assisted approach compared to the open approach, however, it was also associated with greater residual fibroid burden when measured twelve weeks after surgery [53]. With specific regard to fertility post robot-assisted myomectomy, of 872 women undergoing myomectomy 107 conceived resulting in 127 pregnancies and 92 deliveries. The uterine rupture rate was $1.1 \%$ similar to those reported post laparoscopic and open myomectomy [54].

\subsection{Fertility: Tubal Re-Anastomosis}

Bedaiwy et al. in their paper entitled Robotic tubal anastomosis: technical aspects, clearly outline the surgical technique and principles aided by detailed illustrations [55]. There are few published studies assessing the role of robot-assisted surgery in fertility. A non-randomized cohort study comparing open to robot-assisted tubal reanastomosis found the robot-assisted approach was associated with a longer operative time and a shorter LOS. The robotic approach was associated with higher tubal pregnancies (4 vs. 1 ) and a lower rate of spontaneous pregnancies (2 vs. 1) despite a follow-up time of only 8.9 months [56]. A recent paper aimed at comparing effectiveness and safety over the three surgical modalities found no data for evaluation from across multiple databases. They concluded a RCT was required to answer this question [57].

\subsection{Fertility: Interval Cervical Suture Placement}

In 2007 the first case report of robot-assisted abdominal cerclage was published. Since then case reports have confirmed the robotic approach is associated with short duration of stay, minimal blood loss [58] Robotic Sutures have been placed at the time of robot-assisted radical trachelectomy [59] and also during pregnancy [60] with no additional perioperative complications. Persson et al. identified that cervical suture placement at the time of robot-assisted trachelectomy is significantly more precise [61].

Case reports have been published detailing successful pregnancies following robot-assisted suture placement $[62,63]$.

\subsection{Urogynecology: Sacrocolpopexy and Hysteropexy}

The abdominal sacrocolpopexy remains the gold standard for the treatment of vaginal vault prolapse (VVP) despite the introduction of newer techniques such as vaginal mesh kits [64]. Laparoscopic sacrocolpopexy has been shown to have similar outcomes with re-operation rates of approximately $6 \%-7 \%$ and a mesh erosion rate of 3\% [65]. Furthermore, conversion rates reduced with increased operator experience [65]. To date there is only one randomized controlled trial comparing laparoscopic with robotic sacrocolpopexy there was no functional differences between the two groups, the robot was associated with increased cost, increased operative time and pain. [66]. A further study by White comparing three approaches, robotic, laparoscopic and single port revealed no difference in pain, length of stay, blood loss or operating time between the three [67], with good short- 
term functional outcomes. Further studies confirm the good functional results using the robot showing it to be efficacious in the management of VV P $[68,69]$ with a low complication rate and high patient satisfaction [70]. The robotic approach may assist the surgeon in dissecting over the sacral promontory [71]. A drawback to the laparoscopic approach is the associated technical difficulty in placing sutures [72]. While, open sacrocolpopexy is generally associated with greater blood loss, longer hospital stay, delayed return of bowel function, increased postoperative pain and wound complications [73].

Hysteropexy utilizes many techniques and approaches to restore uterine anatomy where uterine preservation is required [74]. Success rates are similar for all three approaches (open/laparoscopic/robot-assisted) varying from $87 \%$ - 98\% [75-77]. Successful pregnancies have been reported following laparoscopic hysteropexy however the long-term effects of pregnancy on the surgery are not fully appreciated yet [78]. Lee et al. in their study on the safety and feasibility of sacrohysteropexy for the treatment of prolapse concluded that the surgery was associated with minimal blood loss and had excellent subjective and objective success rates making it a safe and feasible surgical option in the management of pelvic organ prolapse where uterine preservation is required [79].

\subsection{Urogynecology: Vesicovaginal Fistula Repair}

The robot-assisted approach has been used in the surgical management of vesicovaginal fistula repair. The robot technology allows a complicated laparoscopic procedure to be performed safely with good results. Vesicovaginal fistulae have been effectively treated using the robotassisted approach with minimal blood loss, short length of stay and recurrence rates [80,81].

\section{How Safe Is Robot-Assisted Surgery?}

The introduction of new technology brings new challenges especially for the Surgeon and the theatre team. One of the major technical issues that may arise is a robot malfunction dealing with these issues intraoperatively is challenging for the entire team. Thankfully this is uncommon, however it does occur highlighting the need to counsel patients and to have a contingency plan. Studies recommend conventional laparoscopic suturing skills should be maintained as a requirement on the curriculum thus allowing the surgery to continue using minimally invasive approach if required [82]. The incidence of device failure rate is reported as $0.2 \%-0.4 \%$ [83]. Technical challenges faced by Surgeons performing robot-assisted gynecological oncological procedures included robotic arm malfunction (18\%), light or camera cord malfunction (18\%), instrument failure (10\%), power failure (9\%), port problems (18\%) and miscellaneous (27\%). All surgeons performing robotic surgery must become familiar with troubleshooting robotic technology and associated equipment. Failure to do so may add time and technical difficulty to robotic cases [84]. The FDA maintains a database of manufacturer and user facility device experience (MAUDE) where all users of devices report robot malfunctions and there outcomes. In 2008, a review of the MAUDE database identified 168 reported cases of robot malfunction approximately of which $4.8 \%$ were associated with patient injury. However, with time MAUDE database reported incidences of instrument failure have increased with 528 reports of 565 instrument failures over two years from January 2009 and December 2010. Friedman et al. divided the instrument failures into five groups depending on the reported failure: 1 : Wrist or tool-tip failures (285), 2: Cautery instrument failures (174), 3: Instrument shaft failures (76), 4: Cable failure (29) and 5: control housing failures (1) [85]. In general surgery in a single university unit Buchs et al. recorded a robotic malfunction rate of $3.4 \%$ (18/526) over a seven-year period. Instrument failure accounted for $50 \%$ (9/18) of cases, 22\% (4/18) occurred due to robotic ARM failures, $16 \%(3 / 18)$ derived from console errors, the remaining $12 \%(2 / 18)$ failure occurred in the optic unit. Of note the failure rate decreased with increased operator and team experience [86].

Patient positioning is of great importance to minimize the potential adversarial outcomes associated with long operative times. In a single unit study nerve injury associated with positioning during urological robotic surgery had an incidence of $6.6 \%$ worryingly $23 \%$ of these persisted passed six months. The injury rate was significantly affected by operative time and ASA group (American Society of Anesthetists). Therefore, patients undergoing long surgeries should be counseled regarding the risk of nerve injury especially if they have multiple comorbidities [87].

Checklists have been used as an intervention to prevent these failures by promoting a team-working culture, standardizing practice, allowing the detection of potential errors and improving patient safety as a whole. One example is the WHO surgical safety checklist. Another example, the Healthcare Failure Mode and Effects Analysis (HFMEA) protocol has been widely used across organizations. HFMEA is a powerful systems evaluation tool developed by the US Veterans Affairs National Centre for Patient Safety. It is a step-by-step process that involves the multidisciplinary team in identifying potential causes of error within a system through the use of flow diagrams, hazards scoring and decision tree analysis. Potential errors are prioritized according to severity, frequency/probability, criticality, detectability and existing 
control measures. The final process includes taking steps to implement solutions, minimize errors and avoid adverse events [88]. In a recent study using the HFMEA specific hazards were identified, e.g. patient positioning, port placement, robot docking/de-docking and robotic and laparoscopic equipment checks, which were considered to be important in robot-assisted urological procedures and which are not extensively covered by other checklists [89]. A robot-specific checklist was developed which was specific to the unit with the aim of allowing the detection of potential errors and improving patient safety as a whole. Units where robot-assisted surgery is performed need to implement safety checklists and ensure theatre teams are trained in troubleshooting for technical malfunctions thereby decreasing the potential negative impact of robotic surgery on patients.

\section{Which Approach Is Best for Surgeon Ergonomics?}

Robot-assisted surgery attempts to overcome some of the limitations of laparoscopic surgery while retaining the benefits of a minimally invasive approach. Specific improvements associated with robot-assisted surgery include better visualization through the use of three-dimensional magnification, availability of tools with 7 degrees of freedom that mimic hand movements along with improved ergonomics and more intuitive hand-eye coordination when controlling surgical instruments [90-92]. However, this has been achieved at the cost of haptic and tactile feedback, as a result of the instruments being indirectly manipulated by the surgeon [93].

Lawson et al. [94] assessing the differences between musculoskeletal discomfort and ergonomic strain in laparoscopic versus robotic surgery for gastric bypass surgery found that robotic cases were associated with more discomfort in the neck, while laparoscopic cases were associated with greater discomfort in the upper back and in both shoulders. Furthermore, analysis of ergonomic positioning during the procedures found that laparoscopic surgery was associated with poorer ergonomic positioning of the upper arm, lower arm, wrist and wrist twist, while robot-assisted surgery scored lower for trunk positioning [94]. While Craven et al. studied the ergonomic deficits in robotic gynecologic oncology surgery revealing high rapid upper limb assessment RULA) survey scores, which correlated with high Strain index (SI) scores. The RULA survey is an ergonomic assessment and prioritization method for determining posture, force and frequency concerns with focus on the upper limb, while the SI uses multiplicative interactions to identify jobs that are potentially hazardous. They concluded that the deficits were hazardous to the surgeons and suggested a need for modification and intervention [95]. However the ability to generalize based on studies for specific surgical indications is limited, as the advantage of robotic-assisted surgery significantly depends on the type of the procedure [92].

With obesity increasing throughout the developed world patient habitus often precludes them from laparoscopic surgery, however they may have robot-assisted surgery performed with similar benefits. More complex procedures can be undertaken robotically than with traditional straight stick surgery.

\section{Robot-Assisted Surgery Learning Curves}

Three distinct phases exist in the learning curves associated with robot-assisted surgery [96]. With regard to colorectal surgery the first phase or the initial phase occurred over the first 15 cases during this phase the operating time decreased. The second phase or plateau phase occurred over the next ten cases, during this phase the operator becomes more competent with the robotic technology. The third phase or the mastery phase occurred for the subsequent cases. During the mastery phase the complexity of the cases undertaken increased. The operative time may also increase reflecting the complexity of the surgical procedure. In gynecological surgery the learning curves range from 20 cases for hysterectomy and pelvic lymphadenopathy for endometrial cancer [97], 50 cases for benign hysterectomies [98], and 10 cases for sacrocolpopexy [99]. Compared to this the learning curve associated with laparoscopic sacrocolpopexy is linear and reported as between 18 - 24 cases [100]. A benefit of the robotic approach is that it maintains the benefits of laparoscopy while reducing the technical difficulties $[68,70,101]$.

Specific surgical techniques have also been assessed with regard to their learning curves. A study comparing the learning curves for robot versus laparoscopic surgical skills highlighted that with regard to suturing and dexterity skills the robot allowed for quicker performance than laparoscopy [102]. Ng et al. made the following recommendations to shorten the learning curve. Firstly have a designated theatre team, with no introduction of new members until 20 cases have been performed. Secondly, patient positioning is of paramount importance and should be standardized for all cases and lastly familiarization with the instruments sets is required before any deviation is considered [103].

\section{Training in Robotic Surgery}

Traditionally the surgical apprenticeship relied on the Halstedian model of "see one, do one, teach one". However, with time the realization is there that this model is inadequate to train surgeons to the highest level without impacting on patient care [104]. The concept of training and surgical education changed with the introduction of 
robotic surgery. Its appearance has created new challenges to ensure proper training and avoid subjecting patients to unnecessary risk. Increased scrutiny of credentialing and medico-legal aspects of robotic surgery have reinforced the importance of training and have led to a number of papers outlining pathways to facilitate this [105,106]. Learning tools for robotic surgery include: simulators, dual consoles, robotic courses and proctoring.

\subsection{Robotic Simulators}

Buchs et al. in the World Journal of Surgery reviewed the learning tools and simulation in Robotic Surgery. Even with a relative paucity of published reports on robotic simulators, and the lack of study in favor of one simulator over another, the trend is clearly in favor of virtual training [107]. Currently there are four commercially available simulators. The Mimic dV-Trainer (MdVT) (Mimic Technologies, Seattle, WA, USA) is a small, tabletop-sized, stand-alone simulator that replicates the da Vinci robot. The da Vinci Skills Simulator is the first virtual reality simulator produced by Intuitive Surgical that is integrated with the da Vinci Si console. It integrates the Mimic virtual reality tasks using the da Vinci surgeon console as the user interface. The robotic surgical simulator (RoSS) system (Simulated Surgical Systems, Williamsville, NY, USA) was reported as being realistically close to the da Vinci console for virtual simulation and instrumentation. Finally, the SEP-Robot (SimSurgery, Oslo, Norway) is another virtual robotic simulator. It has a console connected to two instruments with seven degrees of freedom. Unlike the robotic system, however, the SEP-Robot does not provide three-dimensional images.

Virtual reality simulation should be part of the robotic curriculum, as should the use of a dual console, robotic courses, and proctoring. Various societies for robotic surgery are currently at work on a clear curriculum for the new generation of robotic surgeons, which hopefully will lead to standardization [107]. Trainees recognize the benefit of simulation training a questionnaire based study of a group of American urologic association trainees concluded Trainees believe that the simulator replicates real-life robotic console movements and almost all believe they would be benefit from having access to robotic simulation [108]. Patient based training also has a negative impact on the cost of robotic surgery with specific regard to operating time and patient safety. Rehman et al. performed a health economic evaluation of RoSS. During the period of a year they assessed the time spent on the RoSS console, they converted the time to training time and assessed the loss of operating room time and revenue if the RoSS was not available. They concluded the RoSS is a cost effective surgical simulator for implementation of a simulation-based robot-assisted surgical training program [109].

\subsection{Training Courses}

Training courses on robotic surgery are typically performed using inanimate, animal, or cadaver models. The length of the course varies from several hours to several days, sometimes even weeks in a mini-fellowship situation. The content depends on the population on the course. Inanimate exercises offer a cost-effective and robot-agnostic approach to training surgeons [110-112]. They can be designed to target specific (or a subset of) technical skills needed to understand the basic functionality of a robotic system [105,113]. With various levels of difficulty, a continuum of inanimate exercises can guide surgeons of different abilities through their initial learning curves. Inanimate exercises for learning the fundamentals of laparoscopic surgery can be expanded to effectively target robot-specific skills [114]. In order to be useful training tools, inanimate exercises must both challenge specific technical skills of using a robotic surgical system and have validated metrics so that surgeons can accurately track their performance. [115]. For certain, the advent of excellent surgical simulators and structured inanimate exercises has provided tools for novice surgeons to acquire console skills in a safe and structured environment. This will enhance their operating performance and reduce aspects of the learning curve such as operating time; however, the lack of availability of in vivo training opportunities greatly limits the applicability of this method of surgical training [116].

\subsection{Dual Console}

Introduction of the da Vinci Si system has given surgeons a second robotic console, facilitating collaboration between proctor and trainee. The mentoring console has two collaborative modes: 1) the swap mode allows the mentor and trainee to operate simultaneously and actively swap control of the robotic arms. 2) The nudge mode allows them to have control simultaneously, sharing the two robotic arms.

\subsection{Live Surgery and Proctoring}

Live case observation remains an important component of a robotic training program [117] and allows the trainee to become familiar with the steps of a specific robotic procedure. Proctoring is defined as direct supervision by an expert during the initial phase of training and the learning curve [117]. It provides a safe environment during the introduction of a new technique and prevents surgeons from performing procedures before they have mastered the technique.

The reality is that simulators, dual consoles, and robotic courses should play an important role in bridging 
the gap between early surgical skills and effective performance using the robot in a clinical setting without subjecting patients to unnecessary risk. It is also important to have tools that provide an objective means by which to evaluate a trainee's performance in anticipation of their ultimate graduation [118]. Physicians in training can acquire robotic surgery competency. Participants who acquire skills faster regain robotic skills faster after a training hiatus, but, on retraining, all participants can regain equivalent competence. This information provides a benchmark for a simulator training program [119]. However, once acquired robotic surgical skills deteriorate without use in one study robotic surgical skills degraded significantly within 4 weeks of inactivity in newly trained surgeons [120].

\section{Conclusions}

Robot-assisted surgery has been shown to be associated with improved patient outcomes. To maintain these improved outcomes surgical teams must receive training encompassing troubleshooting for robot specific technical issues and maintain laparoscopic skills. Robot-assisted surgery may also bestow a benefit upon the surgeon with regard to improved ergonomics. However, further studies are required in this area.

Finally, with obesity increasing throughout the developed world patient habitus often precludes them from laparoscopic surgery, however, they may have robot-assisted surgery performed with similar benefits. More complex procedures can be undertaken robotically than with traditional straight stick surgery. Highlighting there is a role for robot-assisted surgery in gynecology and all other surgical specialties.

\section{REFERENCES}

[1] O. E. O’Sullivan and B. A. O’Reilly, "Robot-Assisted Surgery:-Impact on Gynaecological and Pelvic Floor Reconstructive Surgery,” International Urogynecology Journal, Vol. 23, No. 9, 2012, pp. 1163-1173. http://dx.doi.org/10.1007/s00192-012-1790-3

[2] M. Reza, et al., "Meta-Analysis of Observational Studies on the Safety and Effectiveness of Robotic Gynaecological Surgery,” British Journal of Surgery, Vol. 97, No. 12, 2010, pp. 1772-1783. http://dx.doi.org/10.1002/bjs.7269

[3] A. P. Advincula and T. Falcone, "Laparoscopic Robotic Gynecologic Surgery,” Obstetrics and Gynecology Clinics of North America, Vol. 31, No. 3, 2004, pp. 599-609. http://dx.doi.org/10.1016/j.ogc.2004.05.004

[4] C. Cronin, M. Hewitt, I. Harley, K. O’Donoghue and B. A. O’Reilly, "Robot-Assisted Laparoscopic Cervical Cerclage as an Interval Procedure,” Gynecological Surgery, Vol. 9, No. 3, 2012, pp. 317-321. http://dx.doi.org/10.1007/s10397-012-0725-9

[5] (CADTH), C.A.f.D.a.T.i.H., "Robot-Assisted Surgery ver- sus OPen Surery and Laparoscopic Surgery: Clinical and Cost-Effectiveness Analyses,” 2010.

[6] C. S. Camberlin, A. Leys and M. De Laet, "Robot-Assisted Surgery: Health Technology Assessment,” B.H.C.K.C. (KCE), Editor, 2009.

[7] HIQA, "Health Technology Assessment of Robot-Assisted Surgery in Selected Surgical Procedures,” H.I.a.Q. Authority, Editor, Dublin, 2012.

[8] Intuitive Surgical. http://www.intuitivesurgical.com/company/profile.html

[9] R. Reynolds and A. P. Advincula, "Robot-Assisted Laparoscopic Hysterectomy: Technique and Initial Experience," American Journal of Surgery, Vol. 191, No. 4, 2006, pp. 555-560. http://dx.doi.org/10.1016/j.amjsurg.2006.01.011

[10] M. C. Bell, et al., "Comparison of Outcomes and Cost for Endometrial Cancer Staging via Traditional Laparotomy, Standard Laparoscopy and Robotic Techniques," Gynecologic Oncology, Vol. 111, No. 3, 2008, pp. 407-411. http://dx.doi.org/10.1016/j.ygyno.2008.08.022

[11] J. F. Boggess, et al., "A Case-Control Study of RobotAssisted Type III Radical Hysterectomy with Pelvic Lymph Node Dissection Compared with Open Radical Hysterectomy,” American Journal of Obstetrics \& Gynecology, Vol. 199, No. 4, 2008, pp. 357.e1-7.

[12] J. F. Boggess, et al., "A Comparative Study of 3 Surgical Methods for Hysterectomy with Staging for Endometrial Cancer: Robotic Assistance, Laparoscopy, Laparotomy,” American Journal of Obstetrics \& Gynecology, Vol. 199, No. 4, 2008, pp. 360.e1-9.

[13] S. A. DeNardis, et al., "Robotically Assisted Laparoscopic Hysterectomy versus Total Abdominal Hysterectomy and Lymphadenectomy for Endometrial Cancer," Gynecologic Oncology, Vol. 111, No. 3, 2008, pp. 412-417. http://dx.doi.org/10.1016/j.ygyno.2008.08.025

[14] R. Estape, et al., "A Case Matched Analysis of Robotic Radical Hysterectomy with Lymphadenectomy Compared with Laparoscopy and Laparotomy," Gynecologic Oncology, Vol. 113, No. 3, 2009, pp. 357-361.

http://dx.doi.org/10.1016/j.ygyno.2009.03.009

[15] J. P. Geisler, et al., "Robotically Assisted Laparoscopic Radical Hysterectomy Compared with Open Radical Hysterectomy,” International Journal of Gynecological Cancer, Vol. 20, No. 3, 2010, pp. 438-442. http://dx.doi.org/10.1111/IGC.0b013e3181cf5c2c

[16] A. Gocmen, F. Sanlikan and M. G. Ucar, "Comparison of Robotic-Assisted Surgery Outcomes with Laparotomy for Endometrial Cancer Staging in Turkey," Archives of Gynecology and Obstetrics, Vol. 282, No. 5, 2010, pp. 539545. http://dx.doi.org/10.1007/s00404-010-1593-z

[17] L. A. Cantrell, et al., "Survival Outcomes for Women Undergoing Type III Robotic Radical Hysterectomy for Cervical Cancer: A 3-Year Experience,” Gynecologic Oncology, Vol. 117, No. 2, 2010, pp. 260-265. http://dx.doi.org/10.1016/j.ygyno.2010.01.012

[18] D. S. Veljovich, et al., "Robotic Surgery in Gynecologic Oncology: Program Initiation and Outcomes after the First Year with Comparison with Laparotomy for Endometrial Cancer Staging,” American Journal of Obstetrics 
\& Gynecology, Vol. 198, No. 6, 2008, pp. 679.e1-10.

[19] H. W. Schreuder, et al., "From Open Radical Hysterectomy to Robot-Assisted Laparoscopic Radical Hysterectomy for Early Stage Cervical Cancer: Aspects of a Single Institution Learning Curve,” Gynecological Surgery, Vol. 7, No. 3, 2010, pp. 253-258.

http://dx.doi.org/10.1007/s10397-010-0572-5

[20] L. G. Seamon, et al., "Comprehensive Surgical Staging for Endometrial Cancer in Obese Patients: Comparing Robotics and Laparotomy,” Obstetrics \& Gynecology, Vol. 114, No. 1, 2009, pp. 16-21.

[21] E. J. Nam, et al., “A Case-Control Study of Robotic Radical Hysterectomy and Pelvic Lymphadenectomy Using 3 Robotic Arms Compared with Abdominal Radical Hysterectomy in Cervical Cancer,” International Journal of Gynecological Cancer, Vol. 20, No. 7, 2010, pp. 12841289. http://dx.doi.org/10.1111/IGC.0b013e3181ef0a14

[22] N. Nevadunsky, R. Clark, S. Ghosh, M. Muto, R. Berkowitz, A. Vitonis, et al., "Comparison of Robot-Assisted Total Laparoscopic Hysterectomy and Total Abdominal Hysterectomy for Treatment of Endometrial Cancer in Obese and Morbidly Obese Patients," Journal of Robotic Surgery, Vol. 4, No. 4, 2010, pp. 247-252. http://dx.doi.org/10.1007/s11701-010-0222-y

[23] C. A. Matthews, et al., "Evaluation of the Introduction of Robotic Technology on Route of Hysterectomy and Complications in the First Year of Use," American Journal of Obstetrics \& Gynecology, Vol. 203, No. 5, 2010, pp. 499. e1-5.

[24] M. P. Lowe, “A Comparison of Robot-Assisted and Traditional Radical Hysterectomy for Early-Stage Cervical Cancer,” Journal of Robotic Surgery, Vol. 3, No. 1, 2009, pp. 19-23. http://dx.doi.org/10.1007/s11701-009-0131-0

[25] A. Maggioni, et al., "Robotic Approach for Cervical Cancer: Comparison with Laparotomy: A Case Control Study," Gynecologic Oncology, Vol. 115, No. 1, 2009, pp. 60-64. http://dx.doi.org/10.1016/j.ygyno.2009.06.039

[26] M. Goel, T. Zollinger and D. Moore, "Surgical Staging of Endometrial Cancer: Robotic versus Open Technique Outcomes in a Contemporary Single Surgeon Series,” Journal of Robotic Surgery, Vol. 5, No. 2, 2011, pp. 109-114. http://dx.doi.org/10.1007/s11701-010-0239-2

[27] D. Halliday, S. Lau, Z. Vaknin, C. Deland, M. Levental, E. McNamara, et al., "Robotic Radical Hysterectomy: Comparison of Outcomes and Cost," Journal of Robotic Surgery, Vol. 4, No. 4, 2010, pp. 211-216. http://dx.doi.org/10.1007/s11701-010-0205-z

[28] A. Gocmen, F. Sanlikan and M. Ucar, "Comparison of Outcomes between Laparotomy and Robotic Technique for Cervical Cancer," Journal of Robotic Surgery, Vol. 4, No. 2, 2010, pp. 123-127. http://dx.doi.org/10.1007/s11701-010-0199-6

[29] Y. W. Jung, et al., "Robot-Assisted Staging Using Three Robotic Arms for Endometrial Cancer: Comparison to Laparoscopy and Laparotomy at a Single Institution,” Journal of Surgical Oncology, Vol. 101, No. 2, 2010, pp. 116-121.

[30] E. M. Ko, et al., "Robotic versus Open Radical Hysterectomy: A Comparative Study at a Single Institution,” Gy- necologic Oncology, Vol. 111, No. 3, 2008, pp. 425-430. http://dx.doi.org/10.1016/j.ygyno.2008.08.016

[31] J. Cardenas-Goicoechea, S. Adams, S. B. Bhat and T. C. Randall, "Surgical Outcomes of Robotic-Assisted Surgical Staging for Endometrial Cancer Are Equivalent to Traditional Laparoscopic Staging at a Minimally Invasive Surgical Center,” Gynecologic Oncology, Vol. 117, No. 2, 2010, pp. 224-228. http://dx.doi.org/10.1016/j.ygyno.2010.01.009

[32] P. A. Gehrig, L. A. Cantrell, A. Shafer, L. N. Abaid, A. Mendivil and J. F. Boggess, "What Is the Optimal Minimally Invasive Surgical Procedure for Endometrial Cancer Staging in the Obese and Morbidly Obese Woman?” Gynecologic Oncology, Vol. 111, No. 1, 2008, pp. 41-45. http://dx.doi.org/10.1016/j.ygyno.2008.06.030

[33] B. N. Giep, H. N. Giep and H. B. Hubert, "Comparison of Minimally Invasive Surgical Approaches for Hysterectomy at a Community Hospital: Robotic-Assisted Laparoscopic Hysterectomy, Laparoscopic-Assisted Vaginal Hysterectomy and Laparoscopic Supracervical Hysterectomy,” Journal of Robotic Surgery, Vol. 4, No. 3, 2010, pp. 167-175. http://dx.doi.org/10.1007/s11701-010-0206-y

[34] D. O. Holtz, G. Miroshnichenko, M. O. Finnegan, M. Chernick and C. J. Dunton, "Endometrial Cancer Surgery Costs: Robot vs Laparoscopy,” Journal of Minimally Invasive Gynecology, Vol. 17, No. 4, 2010, pp. 500-503. http://dx.doi.org/10.1016/j.jmig.2010.03.012

[35] P. C. Lim, E. Kang and D. H. Park, “A Comparative Detail Analysis of the Learning Curve and Surgical Outcome for Robotic Hysterectomy with Lymphadenectomy versus Laparoscopic Hysterectomy with Lymphadenectomy in Treatment of Endometrial Cancer: A Case-Matched Controlled Study of the First One Hundred Twenty Two Patients," Gynecologic Oncology, Vol. 120, No. 3, 2011, pp. 413-418. http://dx.doi.org/10.1016/j.ygyno.2010.11.034

[36] C. Nezhat, O. Lavie, M. Lemyre, O. Gemer and L. Bhagan, "Laparoscopic Hysterectomy with and without a Robot: Stanford Experience,” JSLS: Journal of the Society of Laparoendoscopic Surgeons, Vol. 13, No. 2, 2009, pp. 125128.

[37] T. N. Payne and F. R. Dauterive, “A Comparison of Total Laparoscopic Hysterectomy to Robotically Assisted Hysterectomy: Surgical Outcomes in a Community Practice," Journal of Minimally Invasive Gynecology, Vol. 15, No. 3, 2008, pp. 286-291. http://dx.doi.org/10.1016/j.jmig.2008.01.008

[38] D. Sarlos, L. Kots, N. Stevanovic and G. Schaer, "Robotic Hysterectomy versus Conventional Laparoscopic Hysterectomy: Outcome and Cost Analyses of a Matched CaseControl Study,” European Journal of Obstetrics \& Gynecology and Reproductive Biology, Vol. 150, No. 1, 2010, pp. 92-96. http://dx.doi.org/10.1016/j.ejogrb.2010.02.012

[39] L. G. Seamon, D. E. Cohn, M. S. Henretta, K. H. Kim, M. J. Carlson, G. S. Phillips and J. M. Fowler, "Minimally Invasive Comprehensive Surgical Staging for Endometrial Cancer: Robotics or Laparoscopy?” Gynecologic Oncology, Vol. 113, No. 1, 2009, pp. 36-41. http://dx.doi.org/10.1016/j.ygyno.2008.12.005

[40] B. Sert and V. Abeler, "Robotic Radical Hysterectomy in 
Early-Stage Cervical Carcinoma Patients, Comparing Results with Total Laparoscopic Radical Hysterectomy Cases. The Future Is Now?” International Journal of Medical Robotics and Computer Assisted Surgery, Vol. 3, No. 3, 2007, pp. 224-228. http://dx.doi.org/10.1002/rcs.152

[41] A. R. Shashoua, D. Gill and S. R. Locher, "Robotic-Assisted Total Laparoscopic Hysterectomy versus Conventional Total Laparoscopic Hysterectomy,” JSLS: Journal of the Society of Laparoendoscopic Surgeons, Vol. 13, No. 3, 2009, pp. 364-369.

[42] E. Lambaudie, F. Narducci, M. Bannier, C. Jauffret, N. Pouget, E. Leblanc and G. Houvenaeghel, "Role of RobotAssisted Laparoscopy in Adjuvant Surgery for Locally Advanced Cervical Cancer,” European Journal of Surgical Oncology, Vol. 36, No. 4, 2010, pp. 409-413. http://dx.doi.org/10.1016/j.ejso.2009.12.004

[43] D. Vitobello, G. Siesto, C. Pirovano and N. Ieda, "Surgical Outcomes of Robotic Radical Hysterectomy after Neoadjuvant Chemotherapy for Locally Advanced Cervical Cancer: Comparison with Early Stage Disease,” European Journal of Surgical Oncology: The Journal of the European Society of Surgical Oncology and the British Association of Surgical Oncology, Vol. 39, No. 1, 2013, pp. 87-93.

[44] C. Lonnerfors, T. Bossmar and J. Persson, "Port-Site Metastases Following Robot-Assisted Laparoscopic Surgery for Gynecological Malignancies,” Acta Obstetricia et Gynecologica Scandinavica, Vol. 92, No. 12, 2013, pp. 13611368. http://dx.doi.org/10.1111/aogs.12245

[45] J. F. Magrina, M. Espada, R. Munoz, B. N. Noble and R. M. C. Kho, "Robotic Adnexectomy Compared with Laparoscopy for Adnexal Mass,” Obstetrics \& Gynecology, Vol. 114, No. 3, 2009, pp. 581-584. http://dx.doi.org/10.1097/AOG.0b013e3181b05d97

[46] J. F. Magrina, R. L. Cetta, Y. H. Chang, G. Guevara and P. M. Magtibay, “Analysis of Secondary Cytoreduction for Recurrent Ovarian Cancer by Robotics, Laparoscopy and Laparotomy,” Gynecologic Oncology, Vol. 129, No. 2, 2013, pp. 336-340. http://dx.doi.org/10.1016/j.ygyno.2013.01.015

[47] C. Nezhat, M. Lewis, S. Kotikela, A. Veeraswamy, L. Saadat, B. Hajhosseini and C. Nezhat, "Robotic versus Standard Laparoscopy for the Treatment of Endometriosis," Fertility and Sterility, Vol. 94, No. 7, 2010, pp. 2758-2760. http://dx.doi.org/10.1016/j.fertnstert.2010.04.031

[48] G. Siesto, N. Ieda, R. Rosati and D. Vitobello, "Robotic Surgery for Deep Endometriosis: A Paradigm Shift," The International Journal of Medical Robotics + Computer Assisted Surgery: MRCAS, 2013.

[49] G. Nakib, V. Calcaterra, F. Scorletti, P. Romano, I. Goruppi, S. Mencherini, L. Avolio and G. Pelizzo, "Robotic Assisted Surgery in Pediatric Gynecology: Promising Innovation in Mini Invasive Surgical Procedures,” Journal of Pediatric and Adolescent Gynecology, Vol. 26, No. 1, 2013, pp. e5e7. http://dx.doi.org/10.1016/j.jpag.2012.09.009

[50] J. M. Gobern, C. J. Rosemeyer, J. F. Barter and A. J. Steren, "Comparison of Robotic, Laparoscopic and Abdominal Myomectomy in a Community Hospital,” JSLS: Journal of the Society of Laparoendoscopic Surgeons, Vol. 17, No.
1, 2013, pp. 116-120.

http://dx.doi.org/10.4293/108680812X13517013317473

[51] E. E. Barakat, M. A. Bedaiwy, S. Zimberg, B. Nutter, M. Nosseir and T. Falcone, "Robotic-Assisted, Laparoscopic and Abdominal Myomectomy: A Comparison of Surgical Outcomes,” Obstetrics \& Gynecology, Vol. 117, No. 2, 2011, pp. 256-265. http://dx.doi.org/10.1097/AOG.0b013e318207854f

[52] C. J. Ascher-Walsh and T. L. Capes, "Robot-Assisted Laparoscopic Myomectomy Is an Improvement over Laparotomy in Women with a Limited Number of Myomas," Journal of Minimally Invasive Gynecology, Vol. 17, No. 3, 2010, pp. 306-310.

http://dx.doi.org/10.1016/j.jmig.2010.01.011

[53] L. Griffin, J. Feinglass, A. Garrett, A. Henson, L. Cohen, A. Chaudhari and A. Lin, "Postoperative Outcomes after Robotic versus Abdominal Myomectomy,” JSLS: Journal of the Society of Laparoendoscopic Surgeons, Vol. 17, No. 3, 2013, pp. 407-413. http://dx.doi.org/10.4293/108680813X13693422521557

[54] M. C. Pitter, A. R. Gargiulo, L. M. Bonaventura, J. S. Lehman and S. S. Srouji, "Pregnancy Outcomes Following Robot-Assisted Myomectomy,” Human Reproduction, Vol. 28, No. 1, 2013, pp. 99-108.

http://dx.doi.org/10.1093/humrep/des365

[55] M. A. Bedaiwy, E. M. Barakat and T. Falcone, "Robotic Tubal Anastomosis: Technical Aspects,” JSLS: Journal of the Society of Laparoendoscopic Surgeons/Society of Laparoendoscopic Surgeons, Vol. 15, No. 1, 2011, pp. 10-15.

[56] S. P. Dharia Patel, M. P. Steinkampf, S. J. Whitten and B. A. Malizia, "Robotic Tubal Anastomosis: Surgical Technique and Cost Effectiveness,” Fertility and Sterility, Vol. 90, No. 4, 2008, pp. 1175-1179. http://dx.doi.org/10.1016/j.fertnstert.2007.07.1392

[57] K. George, M. S. Kamath and P. Tharyan, "Minimally Invasive versus Open Surgery for Reversal of Tubal Sterilization,” The Cochrane Database of Systematic Reviews, Vol. 2, 2013, Article ID: CD009174.

[58] L. Barmat, G. Glaser, G. Davis and F. Craparo, "Da VinciAssisted Abdominal Cerclage," Fertility and Sterility, Vol. 88, No. 5, 2007, pp. 1437.e1-e3.

[59] J. Persson, P. Kannisto and T. Bossmar, "Robot-Assisted Abdominal Laparoscopic Radical Trachelectomy,” Gynecologic Oncology, Vol. 111, No. 3, 2008, pp. 564-567. http://dx.doi.org/10.1016/j.ygyno.2008.05.034

[60] L. Wolfe, S. De Pasquale, C. D. Adair, C. Torres, S. Stallings, C. Briery and C. Pearce, "Robotic-Assisted Laparoscopic Placement of Transabdominal Cerclage during Pregnancy," American Journal of Perinatology, Vol. 25, No. 10, 2008, pp. 653-655. http://dx.doi.org/10.1055/s-0028-1090591

[61] J. Persson, S. Imboden, P. Reynisson, B. Andersson, C. Borgfeldt and T. Bossmar, "Reproducibility and Accuracy of Robot-Assisted Laparoscopic Fertility Sparing Radical Trachelectomy,” Gynecologic Oncology, Vol. 127, No. 3, 2012, pp. 484-488. http://dx.doi.org/10.1016/j.ygyno.2012.08.022

[62] C. Cronin, M. Hewitt, I. Harley, K. O’Donoghue and B. A. O’Reilly, "Robot-Assisted Laparoscopic Cervical Cerclage as an Interval Procedure,” Gynecological Surgery, Vol. 
9, No. 3, 2012, pp. 317-321. http://dx.doi.org/10.1007/s10397-012-0725-9

[63] A. Gocmen and F. Sanlikan, "Two Live Births Following Robotic-Assisted Abdominal Cerclage in Nonpregnant Women," Case Reports in Obstetrics and Gynecology, Vol. 2013, 2013, Article ID: 256972.

[64] C. Maher, K. Baessler, C. M. A. Glazener, E. J. Adams and S. Hagen, "Surgical Management of Pelvic Organ Prolapse in Women: A Short Version Cochrane Review," Neurourology and Urodynamics, Vol. 27, No. 1, 2008, pp. 3-12. http://dx.doi.org/10.1002/nau.20542

[65] A. M. Ganatra, F. Rozet, R. Sanchez-Salas, E. Barret, M. Galiano, X. Cathelineau and G. Vallancien, "The Current Status of Laparoscopic Sacrocolpopexy: A Review,” European Urology, Vol. 55, No. 5, 2009, pp. 1089-1103. http://dx.doi.org/10.1016/j.eururo.2009.01.048

[66] M. F. Paraiso, J. E. Jelovsek, A. Frick, C. C. G. Chen and M. D. Barber, "Laparoscopic Compared with Robotic Sacrocolpopexy for Vaginal Prolapse: A Randomized Controlled Trial,” Obstetrics \& Gynecology, Vol. 118, No. 5, 2011, pp. 1005-1013. http://dx.doi.org/10.1097/AOG.0b013e318231537c

[67] W. M. White, R. K. Goel, M. A. Swartz, C. Moore, R. R. Rackley and J. H. Kaouk, "Single-Port Laparoscopic Abdominal Sacral Colpopexy: Initial Experience and Comparative Outcomes," Urology, Vol. 74, No. 5, 2009, pp. 10081012. http://dx.doi.org/10.1016/j.urology.2009.02.086

[68] F. Daneshgari, J. C. Kefer, C. Moore and J. Kaouk, "Robotic Abdominal Sacrocolpopexy/Sacrouteropexy Repair of Advanced Female Pelvic Organ Prolaspe (POP): Utilizing POP-Quantification-Based Staging and Outcomes,” BJU International, Vol. 100, No. 4, 2007, pp. 875-879. http://dx.doi.org/10.1111/j.1464-410X.2007.07109.x

[69] E. J. Geller, N. Y. Siddiqui, J. M. Wu and A. G. Visco, "Short-Term Outcomes of Robotic Sacrocolpopexy Compared with Abdominal Sacrocolpopexy,” Obstetrics \& Gynecology, Vol. 112, No. 6, 2008, pp. 1201-1206. http://dx.doi.org/10.1097/AOG.0b013e31818ce394

[70] D. S. Elliott, A. E. Krambeck and G. K. Chow, "Long-Term Results of Robotic Assisted Laparoscopic Sacrocolpopexy for the Treatment of High Grade Vaginal Vault Prolapse,” Journal of Urology, Vol. 176, No. 2, 2006, pp. 655659. http://dx.doi.org/10.1016/j.juro.2006.03.040

[71] A. Gocmen, F. Sanlikan and M. G. Ucar, "Robotic-Assisted Sacrocolpopexy/Sacrocervicopexy Repair of Pelvic Organ Prolapse: Initial Experience,” Archives of Gynecology and Obstetrics, Vol. 285, No. 3, 2011, pp. 683-688.

[72] A. Wattiez, "Laparoscopic Repair of Vaginal Vault Prolapse," Current Opinion in Obstetrics \& Gynecology, Vol. 15, No. 4, 2003, pp. 315-319. http://dx.doi.org/10.1097/01.gco.0000084246.09900.06

[73] J. P. Gilleran, M. Johnson and A. Hundley, "Robotic-Assisted Laparoscopic Mesh Sacrocolpopexy,” Therapeutic Advances in Urology, Vol. 2, No. 5-6, 2010, pp. 195-208.

[74] B. Ridgeway, A. C. Frick and M. D. Walter, "Hysteropexy. A Review,” Minerva Ginecologica, Vol. 60, No. 6, 2008, pp. 509-528.

[75] H. G. Krause, J. T. W. Goh, K. Sloane, P. Higgs and M. P.
Carey, "Laparoscopic Sacral Suture Hysteropexy for Uterine Prolapse,” International Urogynecology Journal, Vol. 17, No. 4, 2006, pp. 378-381. http://dx.doi.org/10.1007/s00192-005-0019-0

[76] B. Feiner, L. Gietelink and C. Maher, “Anterior Vaginal Mesh Sacrospinous Hysteropexy and Posterior Fascial Plication for Anterior Compartment Dominated Uterovaginal Prolapse,” International Urogynecology Journal, Vol. 21, No. 2, 2010, pp. 203-208.

http://dx.doi.org/10.1007/s00192-009-1012-9

[77] N. Price, A. Slack and S. R. Jackson, "Laparoscopic Hysteropexy: The Initial Results of a Uterine Suspension Procedure for Uterovaginal Prolapse,” British Journal of Obstetrics \& Gynaecology, Vol. 117, No. 1, 2010, pp. 62-68. http://dx.doi.org/10.1111/j.1471-0528.2009.02396.x

[78] G. B. Busby and J. Broome, "Successful Pregnancy Outcome Following Laparoscopic Sacrohysteropexy for Second Degree Uterine Prolapse," Gynecological Surgery, Vol. 7, No. 3, 2010, pp. 271-273. http://dx.doi.org/10.1007/s10397-008-0460-4

[79] T. Lee, N. Rosenblum, V. Nitti and B. M. Brucker, "Uterine Sparing Robotic-Assisted Laparoscopic Sacrohysteropexy for Pelvic Organ Prolapse: Safety and Feasibility,” Journal of Endourology/Endourological Society, Vol. 27, No. 9, 2013, pp. 1131-1136. http://dx.doi.org/10.1089/end.2013.0171

[80] O. Melamud, L. Eichel, B. Turbow and A. Shanberg, "Laparoscopic Vesicovaginal Fistula Repair with Robotic Reconstruction,” Urology, Vol. 65, No. 1, 2005, pp. 163-166. http://dx.doi.org/10.1016/j.urology.2004.09.052

[81] B. M. Sundaram, G. Kalidasan and A. K. Hemal, "Robotic Repair of Vesicovaginal Fistula: Case Series of Five Patients,” Urology, Vol. 67, No. 5, 2006, pp. 970-973. http://dx.doi.org/10.1016/j.urology.2005.11.014

[82] D. Kaushik, R. High, C. J. Clark and C. A. LaGrange, "Malfunction of the Da Vinci Robotic System during RobotAssisted Laparoscopic Prostatectomy: An International Survey," Journal of Endourology/Endourological Society, Vol. 24, No. 4, 2010, pp. 571-575. http://dx.doi.org/10.1089/end.2009.0489

[83] D. G. Murphy, A. Bjartell, V. Ficarra, M. Graefen, A. Haese, R. Montironi, F. Montorsi, J. W. Moul, G. Novara, G. Sauter, T. Sulser and H. van der Poel, "Downsides of Robot-Assisted Laparoscopic Radical Prostatectomy: Limitations and Complications,” European Urology, Vol. 57, No. 5, 2010, pp. 735-746. http://dx.doi.org/10.1016/j.eururo.2009.12.021

[84] M. A. Finan and R. P. Rocconi, "Overcoming Technical Challenges with Robotic Surgery in Gynecologic Oncology,” Surgical Endoscopy, Vol. 24, No. 6, 2010, pp. 1256-1260. http://dx.doi.org/10.1007/s00464-009-0756-0

[85] D. C. Friedman, T. S. Lendvay and B. Hannaford, "Instrument Failures for the da Vinci Surgical System: A Food and Drug Administration MAUDE Database Study," Surgical Endoscopy, Vol. 27, No. 5, 2013, pp. 1503-1508. http://dx.doi.org/10.1007/s00464-012-2659-8

[86] N. C. Buchs, F. Pugin, F. Volonté and P. Morel, "Reliability of Robotic System during General Surgical Procedures in a University Hospital," American Journal of Surgery, 
Vol. 207, No. 1, 2013, pp. 84-88.

[87] J. T. Mills, M. B. Burris, D. J. Warburton, M. R. Conaway, N. S. Schenkman and T. L. Krupski, "Positioning Injuries Associated with Robotic Assisted Urological Surgery,” The Journal of Urology, Vol. 190, No. 2, 2013, pp. 580-584. http://dx.doi.org/10.1016/j.juro.2013.02.3185

[88] J. DeRosier, E. Stalhandske, J. P. Bagian and T. Nudell, "Using Health Care Failure Mode and Effect Analysis: The VA National Center for Patient Safety's Prospective Risk Analysis System," The Joint Commission Journal on Quality Improvement, Vol. 28, No. 5, 2002, pp. 248-267, 209.

[89] K. Ahmed, N. Khan, M. S. Khan and P. Dasgupta, "Development and Content Validation of a Surgical Safety Checklist for Operating Theatres that Use Robotic Technology,” BJU International, Vol. 111, No. 7, 2013, pp. 11611174. http://dx.doi.org/10.1111/bju.12010

[90] R. F. Coelho, S. Chauhan, K. J. Palmer, B. Rocco, M. B. Patel and V. R. Patel, "Robotic-Assisted Radical Prostatectomy: A Review of Current Outcomes,” BJU International, Vol. 104, No. 10, 2009, pp. 1428-1435. http://dx.doi.org/10.1111/j.1464-410X.2009.08895.x

[91] R. F. Coelho, B. Rocco, M. B. Patel, M. A. Orvieto, S. Chauhan, V. Ficarra, S. Melegari, K. J. Palmer and V. R. Patel, "Retropubic, Laparoscopic and Robot-Assisted Radical Prostatectomy: A Critical Review of Outcomes Reported by High-Volume Centers," Journal of Endourology, Vol. 24, No. 12, 2010, pp. 2003-2015. http://dx.doi.org/10.1089/end.2010.0295.

[92] J. H. Rassweiler, M. Hruza, J. Klein, A. S. Goezen and D. Teber, "The Role of Laparoscopic Radical Prostatectomy in the Era of Robotic Surgery,” European Urology Supplements, Vol. 9, No. 3, 2010, pp. 379-387. http://dx.doi.org/10.1016/j.eursup.2010.02.006

[93] A. M. Okamura, "Haptic Feedback in Robot-Assisted Minimally Invasive Surgery,” Current Opinion in Urology, Vol. 19, No. 1, 2009, pp. 102-107. http://dx.doi.org/10.1097/MOU.0b013e32831a478c

[94] E. C. Lawson, M. J. Curet, B. R. Sanchez, R. Schuster and R. Berguer, "Postural Ergonomics during Robotic and Laparoscopic Gastric Bypass Surgery: A Pilot Project," Journal of Robotic Surgery, Vol. 1, No. 1, 2007, pp. 6167. http://dx.doi.org/10.1007/s11701-007-0016-z

[95] R. Craven, J. Franasiak, P. Mosaly and P. A. Gehrig, "Ergonomic Deficits in Robotic Gynecologic Oncology Surgery: A Need for Intervention,” Journal of Minimally Invasive Gynecology, Vol. 20, No. 5, 2013, pp. 648-655. http://dx.doi.org/10.1016/j.jmig.2013.04.008

[96] M. B. Bokhari, C. B. Patel, D. I. Ramos-Valadez, M. Ragupathi and E. M. Haas, "Learning Curve for Robotic-Assisted Laparoscopic Colorectal Surgery,” Surgical Endoscopy, Vol. 25, No. 3, 2011, pp. 855-860. http://dx.doi.org/10.1007/s00464-010-1281-x

[97] L. G. Seamon, J. M. Fowler, D. L. Richardson, M. J. Carlson, S. Valmadre, G. S. Phillips and D. E. Cohn, “A Detailed Analysis of the Learning Curve: Robotic Hysterectomy and Pelvic-Aortic Lymphadenectomy for Endometrial Cancer,” Gynecologic Oncology, Vol. 114, No. 2, 2009, pp. 162-167. http://dx.doi.org/10.1016/j.ygyno.2009.04.017

[98] J. P. Lenihan Jr., C. Kovanda and U. Seshadri-Kreaden, "What Is the Learning Curve for Robotic Assisted Gynecologic Surgery?” Journal of Minimally Invasive Gynecology, Vol. 15, No. 5, 2008, pp. 589-594. http://dx.doi.org/10.1016/j.jmig.2008.06.015

[99] M. N. Akl, J. B. Long, D. L. Giles, J. L. Cornella, P. D. Pettit, A. H. Chen and P. M. Magtibay, "Robotic-Assisted Sacrocolpopexy: Technique and Learning Curve," Surgical Endoscopy, Vol. 23, No. 10, 2009, pp. 2390-2394. http://dx.doi.org/10.1007/s00464-008-0311-4

[100] C. Y. Akladios, D. Dautun, C. Saussine, J. J. Baldauf, C. Mathelin and A. Wattiez, "Laparoscopic Sacrocolpopexy for Female Genital Organ Prolapse: Establishment of a Learning Curve,” European Journal of Obstetrics \& Gynecology and Reproductive Biology, Vol. 149, No. 2, 2010, pp. 218-221. http://dx.doi.org/10.1016/j.ejogrb.2009.12.012

[101] B. A. Kramer, C. M. Whelan, T. M. Powell and B. F. Schwartz, "Robot-Assisted Laparoscopic Sacrocolpopexy as Management for Pelvic Organ Prolapse,” Journal of Endourology, Vol. 23, No. 4, 2009, pp. 655-658. http://dx.doi.org/10.1089/end.2008.0290

[102] P. Yohannes, P. Rotariu, P. Pinto, A. D. Smith and B. R. Lee, "Comparison of Robotic versus Laparoscopic Skills: Is There a Difference in the Learning Curve?” Urology, Vol. 60, No. 1, 2002, pp. 39-45. http://dx.doi.org/10.1016/S0090-4295(02)01717-X

[103] J. S. Ng, Y. F. Fong, P. S. Tong, E. L. Yong and J. J. Low, "Gynaecologic Robot-Assisted Cancer and Endoscopic Surgery (GRACES) in a Tertiary Referral Centre," Annals of the Academy of Medicine Singapore, Vol. 40, No. 5, 2011, pp. 208-212.

[104] J. M. Rodriguez-Paz, M. Kennedy, E. Salas, A. W. Wu, J. B. Sexton, E. A. Hunt and P. J. Pronovost, "Beyond 'See One, Do One, Teach One': Toward a Different Training Paradigm," Quality \& Safety in Health Care, Vol. 18, No. 1, 2009, pp. 63-68.

[105] J. Y. Lee, P. Mucksavage, C. P. Sundaram and E. M. McDougall, "Best Practices for Robotic Surgery Training and Credentialing," The Journal of Urology, Vol. 185, No. 4, 2011, pp. 1191-1197. http://dx.doi.org/10.1016/j.juro.2010.11.067

[106] K. C. Zorn, et al., “Training, Credentialing, Proctoring and Medicolegal Risks of Robotic Urological Surgery: Recommendations of the Society of Urologic Robotic Surgeons," The Journal of Urology, Vol. 182, No. 3, 2009, pp. 1126-1132. http://dx.doi.org/10.1016/j.juro.2009.05.042

[107] N. C. Buchs, F. Pugin, F. Volonté and P. Morel, "Learning Tools and Simulation in Robotic Surgery: State of the Art,” World Journal of Surgery, Vol. 37, No. 12, 2013, pp. 2812-2819. http://dx.doi.org/10.1007/s00268-013-2065-y

[108] D. D. Thiel, V. R. Patel, T. Larson, A. Lannen and R. J. Leveillee, "Assessment of Robotic Simulation by Trainees in Residency Programs of the Southeastern Section of the American Urologic Association,” Journal of Surgical Education, Vol. 70, No. 5, 2013, pp. 571-577. http://dx.doi.org/10.1016/j.jsurg.2013.04.014 
[109] S. Rehman, et al., "Simulation-Based Robot-Assisted Surgical Training: A Health Economic Evaluation,” International Journal of Surgery, Vol. 11, No. 9, 2013, pp. 841846. http://dx.doi.org/10.1016/j.ijsu.2013.08.006

[110] M. T. Goova, L. A. Hollett, S, T. Tesfay, R. B. Gala, N. Puzziferri, F. J. Kehdy and D. J. Scott, "Implementation, Construct Validity and Benefit of a Proficiency-Based KnotTying and Suturing Curriculum,” Journal of Surgical Education, Vol. 65, No. 4, 2008, pp. 309-315. http://dx.doi.org/10.1016/j.jsurg.2008.04.004

[111] G. Sroka, L. S. Feldman, M. C. Vassiliou, P. A. Kaneva, R. Fayez and G. M. Fried, "Fundamentals of Laparoscopic Surgery Simulator Training to Proficiency Improves Laparoscopic Performance in the Operating Room-A Randomized Controlled Trial,” American Journal of Surgery, Vol. 199, No. 1, 2010, pp. 115-120. http://dx.doi.org/10.1016/j.amjsurg.2009.07.035

[112] A. M. Derossis, G. M. Fried, M. Abrahamowicz, H. H. Sigman, J. S. Barkun and J. L. Meakins, "Development of a Model for Training and Evaluation of Laparoscopic Skills," American Journal of Surgery, Vol. 175, No. 6, 1998, pp. 482-487. http://dx.doi.org/10.1016/S0002-9610(98)00080-4

[113] C. Lyons, D. Goldfarb, S. L. Jones, N. Badhiwala, B. Miles, R. Link and B. J. Dunkin, "Which Skills Really Matter? Proving Face, Content and Construct Validity for a Commercial Robotic Simulator,” Surgical Endoscopy, Vol. 27, No. 6, 2013, pp. 2020-2030. http://dx.doi.org/10.1007/s00464-012-2704-7

[114] G. Dulan, R. V. Rege, D. C. Hogg, K. M. Gilberg-Fisher, N. A. Arain, S. T. Tesfay and D. J. Scott, "ProficiencyBased Training for Robotic Surgery: Construct Validity, Workload and Expert Levels for Nine Inanimate Exercises,"
Surgical Endoscopy, Vol. 26, No. 6, 2012, pp. 1516-1521. http://dx.doi.org/10.1007/s00464-011-2102-6

[115] A. M. Jarc and M. Curet, “Construct Validity of Nine New Inanimate Exercises for Robotic Surgeon Training Using a Standardized Setup,” Surgical Endoscopy, 2013. http://dx.doi.org/10.1007/s00464-013-3224-9

[116] D. G. Murphy and C. P. Sundaram, “Comparative Assessment of Three Standardized Robotic Surgery Training Methods,” BJU International, Vol. 112, No. 6, 2013, pp. 713-714.

http://dx.doi.org/10.1111/j.1464-410X.2012.11760.x

[117] H. W. Schreuder, R. Wolswijk, R. P. Zweemer, M. P. Schijven and R. H. Verheijen, "Training and Learning Robotic Surgery, Time for a More Structured Approach: A Systematic Review," BJOG: An International Journal of Obstetrics and Gynaecology, Vol. 119, No. 2, 2012, pp. 137 149.

[118] C. D. Lallas and J. W. Davis, "Robotic Surgery Training with Commercially Available Simulation Systems in 2011: A Current Review and Practice Pattern Survey from the Society of Urologic Robotic Surgeons," Journal of Endourology/Endourological Society, Vol. 26, No. 3, 2012, pp. 283-293. http://dx.doi.org/10.1089/end.2011.0371

[119] N. Zhang and B. D. Sumer, “Transoral Robotic Surgery: Simulation-Based Standardized Training,” JAMA Otolaryngology-Head \& Neck Surgery, Vol. 139, No. 11, 2013, pp. 1111-1117.

[120] E. L. Jenison, et al., "Robotic Surgical Skills: Acquisition, Maintenance and Degradation,” JSLS: Journal of the Society of Laparoendoscopic Surgeons, Vol. 16, No. 2, 2012, pp. 218-228. 